This PDF is a selection from a published volume from the National Bureau of Economic Research

Volume Title: Risk Topography: Systemic Risk and Macro Modeling

Volume Author/Editor: Markus Brunnermeier and Arvind Krishnamurthy, editors

Volume Publisher: University of Chicago Press

Volume ISBN: 0-226-07773-X (cloth); 978-0-226-07773-4 (cloth); 978-0-226-09264-5 (elSBN)

Volume URL: http://www.nber.org/books/brun11-1

Conference Date: April 28, 2011

Publication Date: August 2014

Chapter Title: LEADS on Macroeconomic Risks to and from the Household Sector

Chapter Author(s): Jonathan A. Parker

Chapter URL: http://www.nber.org/chapters/c12551

Chapter pages in book: (p. 183 - 203) 


\title{
LEADS on Macroeconomic Risks to and from the Household Sector
}

\author{
Jonathan A. Parker
}

The household sector is both a propagator of shocks to the economy, as wealth is redistributed across households with differing propensities to consume, and an originator of risky claims held in systemically important places, as losses are shifted from households to creditors such as financial institutions. Information about these exposures, like information generally, is conveyed by prices and so is underproduced by markets. Thus increased public collection, analysis, and distribution of information on household exposures to macroeconomic risk factors can potentially lead to better macroeconomic performance, both through better informed private decision making and through better public policy.

This chapter describes a system for monitoring, measuring, and publicizing exposures to and from the household sector. This system, called the LEADS system, is designed to provide market participants, regulators, and households with additional information to understand the reallocation of resources within, from, and to the household sector in response to macroeconomic events. In short, the system is designed to stress test the balance

Jonathan A. Parker is the International Programs Professor of Management at the MIT Sloan School of Management and a research associate of the National Bureau of Economic Research.

For helpful comments, I thank Markus Brunnermeier, Andrea Eisfeldt, Arvind Krishnamurthy, and participants in the April 2011 NBER conference on systemic risk and macro modeling. This research was funded by the NBER Systemic Risk and Macro Modeling Project and the Kellogg School of Management at Northwestern University. In addition to being faculty at the Kellogg School, I served as an academic consultant and adviser for the Federal Reserve Bank of Chicago and served as a special adviser on financial stability for the US Department of the Treasury during 2009. For acknowledgments, sources of research support, and disclosure of the author's material financial relationships, if any, please see http://www.nber.org/chapters /c12551.ack. 
sheets of the households and include the household sector in measurement of systemic risk.

The LEADS system has three components, of which the first is the main focus of this chapter. The first step is the collection of data on LEADSliabilities, earnings, assets, demographics, and financial sophistication - at the household level. I argue that these categories are the key dimensions to measure, that measurement at the household level is critical for accurate measurement, and that much of this information is available in institutions already subject to government oversight and reporting requirements. The second step in LEADS is the measurement of the exposure of each asset, each liability, and each income stream to macroeconomic risk factors. This step is the subject of much of the field and practice of finance, and describing the vast and evolving set of techniques for this step is beyond this chapter. This component of the system requires historical data on returns (at a minimum) and modeling of future exposures.

The final step is the analysis and release of information. I propose analysis of the implications of changes in risk factors in four important dimensions: the distributional impacts on both liquid wealth and lifetime wealth; the changes in household demand; the effects of balance sheet adjustments on the prices and payouts of claims on the household sector held by other sectors; and the resulting impact on the revenues and liabilities of the government, through possible transfers and de jure and de facto guarantees to the household sector. Such projections necessarily involve household decisions. This information on exposures across groups of households could then be combined with information on financial sophistication. Where exposures to or from the household sector are large and sophistication low, macroeconomic risks may be mispriced or amplified by lack of sophistication and knowledge. ${ }^{1}$ Finally, the results of the analyses could be made publicpotentially pushed in some cases to "unsophisticated" households-and the underlying data made public in a suitably limited form that maintains privacy.

Together the LEADS system would uncover information relevant to addressing the following types of questions that are of interest to market participants and policymakers:

- How risky are loans to the household sector? Is a particular type of aggregate risk concentrated among households with few resources or little sophistication and so represents a potential source of losses for other claims on these households?

1. The focus of this chapter on sophistication in the household sector is not intended to single out or incriminate this sector. Systematic risks could be caused or hidden by lack of sophistication, limited knowledge and biases among legislators, regulators, and courts (as well as financial institutions, businesses, etc.). Lack of sophistication outside the household sector may have been a cause of the recent crisis, and may still cause systemic risk even with the LEADS information. This chapter simply focuses on measurement in the household sector. 
- Is a particular type of macroeconomic or systematic risk held primarily by households with little financial sophistication and so potentially mispriced?

- How exposed is consumer demand to declines in different assets or asset classes? Is a particular type of aggregate risk concentrated in liquid wealth or on households whose demand is highly sensitive to losses?

- How likely are private losses to become public liabilities? Is a particular group of households, like pensioners, holding enough of a specific macroeconomic or systematic risk so that losses might lead to ex post public assistance?

With very narrow exceptions, these questions cannot be answered by analysis of existing data sets.

This chapter-and the NBER Initiative on Systemic Risk and Macro Modeling of which it is a part - are both motivated directly by the credit market disruptions and financial crisis of 2007 and early 2008, the contemporaneous declines in asset values, and the large macroeconomic consequences. At the time, most observers expected that the decline in demand for investment and consumption goods following these events would be both similar to that caused by the stock market decline in the year 2000 and concentrated on the construction sector (e.g., Bernanke 2008). ${ }^{2}$ In fact, consumption demand fell significantly during the Great Recession-more than output - and has been slow to recover after (relative to most previous US recessions).

The financial crisis and recession of 2008 to 2009 illustrate the two main ways in which the household sector is important for measurement of systemic risks. First, household demand is critical for business cycles, and as such the monitoring of households' balance sheets and wealth is a natural part of the monitoring of macroeconomic risks. Second, systemically important institutions hold claims on the household sector, and so understanding the correlated risks of these institutions requires understanding the value of these claims in different macroeconomic scenarios. Section 13.1 contains a discussion of these issues.

Section 13.2 presents the structure of the LEADS data and describes how this structure allows one to measure aggregate risks to and from the household sector. Section 13.3 describes how the LEADS data can be collected and compiled. Current sources of information are disparate, do not cover the same households, lack sufficient detail on asset holdings, and do not measure household sophistication. The data set for the LEADS system can be constructed by merging administrative data on investments and debts

2. There were even reasons to believe the macroeconomic impact would be smaller than in 2000. Housing is consumption, and as house values decline, the (opportunity) cost of housing falls, providing insurance to households that own homes. Further, the structure of mortgages provides households with an option that increases in value when house prices decline, transferring wealth from high-wealth, high-saving households to low-wealth, high-consumption households. 
with a panel survey of households that focuses on demographics, income, and financial sophistication.

Section 13.4 discusses analysis and dissemination. Analysis of the data can use existing tools employed in the study of financial risks and household finances. I sketch a three-step procedure to first measure individual-asset exposures, calculate liquid wealth and lifetime wealth exposures, and map these back to changes in both household demand and the value of claims on households. To allow better management of aggregate risks, the analysis, summary data, and an anonymous random sample of detailed data can be released to the public. Section 13.5 concludes, and an appendix discusses the role of the government in the provision of this type of information.

\subsection{Why Monitor Household Exposures?}

The exposures to and from the household sector are important for monitoring and measuring aggregate risks for three broad reasons.

First, movements in household expenditures amplify and propagate shocks to the economy. This was true in the recession of 2008 to 2009; during and following the recession, sluggish household expenditures have amplified and propagated slowdown. This has also been true more broadly. As Hall (1986 and forthcoming) shows, the volatility of GDP comes primarily from household spending. And long slumps from the Great Depression to the recent recession are arguably amplified by low consumer demand due in part to debt overhang (e.g., Melzer 2010).

Since households own firms and are the government, household demand is exposed to macroeconomic risks through changes in aggregate income and aggregate asset values (and gains or losses on net asset postions with foreign countries). Thus, a major part of risk in household demand can be measured from aggregate data on the share of wealth held in different asset classes and an evaluation of the riskiness of each asset class. But householdlevel data on individual asset holdings and their characteristics can provide a better understanding of the exposure of aggregate demand to asset values.

Any decline in any asset value has a disporportionate impact on household demand if it is accompanied by transfers among households of differing propensities to consume. This disproportionate effect can happen, for example, if shocks redistribute resources between middle-aged households, whose behavior is reasonably approximated by the life cycle model, and younger households, whose behavior is better characterized by the buffer stock model of consumption. ${ }^{3}$ In the recent recession and in the Great

3. See Carroll (1997) and Gourinchas and Parker (2002). Kaplan and Violante (2011) provide a related model. Most current models of the macroeconomy are largely linear, even those with heterogeneous agents, so that the household-level data is not necessary in these models for predicting macroeconomic dynamics. This statement even applies to models with precautionary savings that match the large share of households with low wealth (Krusell and Smith 1998), although these models typically miss the volatility of asset markets. 
Depression, for example, household demand seems to have been reduced by the concentration of losses among households with leverage. ${ }^{4}$

Thus, the household sector has historically been an important proximate source of output volatility and the household sector's response to wealth changes is determined by the distribution of wealth changes both across households and across two measures of wealth: short-term, liquid, financial resources and long-term, illiquid wealth, such as retirment accounts or future income.

The second reason to monitor household exposures is that both the government and systemically important institutions hold financial claims on the household sector. The ability of households to meet these claims and not default in different macroeconomic scenarios determines the exposure of these assets to systematic risks and thus the extent to which those holding the financial claims are exposed.

In the recession of 2008 to 2009 , a significant reason for the depth and severity of the recession was large losses on loans to households that were held by systemically important financial institutions. These exposures may well have been smaller had the exposures to aggregate risk factors of the various dimensions of wealth of the households with mortgages been better understood by market participants or regulators.

The final reason to monitor household exposures is that, as with groups of banks, the government cannot commit ex ante not to make large transfers to groups of households following adverse outcomes. ${ }^{5}$ And in general, monitoring is helpful in dealing with the moral hazard problems that accompany insurance. These types of assistance are public risks that expose aggregate growth to the risks born by these households through increased tax rates and decreased future spending and benefits.

Examples of governments assisting a subset of households that lose significant resources include those following natural disasters, and the bailout of the elderly following the Great Depression with the Social Security system (enacted in 1935 and 1939), which paid retirees benefits starting in 1940 to aid seniors whose wealth was wiped out by the Great Depression. ${ }^{6}$ As long as the government ex post makes transfers to households that have suffered

4. See Fisher (1933), Eggertsson and Krugman (2012), Hall (2011). Parker and VissingJorgensen $(2009,2010)$ find larger consumption declines for high-consumption or high-income households, implying an important role for declines in asset prices and expected future prospects of high-income households.

5. Farhi and Tirole (2012) clarify the point that it is not just that a single institution can be too big to fail, but also groups of institutions. The Troubled Asset Relief Program provided equity investments not just in large banks but in most small banks also.

6. And we may observe it if the Pension Benefit Guaranty Corporation (PGBC) fails or some US states go bankrupt. On the other hand, households facing foreclosure in the current recession were not bailed out. What little assistance that was provided - the Home Affordable Modification Program, which affected less than a million mortgages-focused on overcoming an ex post market inefficiency rather than being a transfer to households. Also, there was no government rescue for the employees of Enron or Arthur Anderson, nor for the victims of the Madoff fraud. 
large losses, it is optimal for the government, like any private insurer, to monitor these households and react to these risks. ${ }^{7}$

These are the reasons that market participants and policymakers benefit from information on household asset holdings, but why does the government have a role in gathering, analyzing, and publicizing this information? There are two main reasons, addressed in more detail in the appendix. First, as a general principle, in markets the social value of information exceeds its private value, so information is underproduced by the market. Given too little information, mistakes are made relative to the economy with the socially optimal amount of information. And mistakes will tend to be based on the common information that exists, so that misestimation leads to coordinated mistakes that are by definition macroeconomic. Second, lack of financial sophistication (such as lack of financial knowledge, limited information processing abilities, and limited time allocated to financial decisions) can lead some households to misprice aggregate risks, both leading to misallocation by other sectors and exposing household demand and claims on households to "mispriced" aggregate risk factors. ${ }^{8}$ While it is efficient to have the downside economic risk held by those most willing to hold it, it is generically inefficient to have it held by those least able to understand it or who most underestimate it.

These considerations imply that data collection and analysis focus on measuring the systematic exposure of two measures of household financial wealth - liquid financial resources over a few years and lifetime wealthfor not just the household sector but also for different households grouped according to consumption response to these two measures of resources, according to their importance for claims on the household sector, according to the likelihood of losses being born by the government, and according to measures of financial sophistication of the household decision makers.

\subsection{LEADS Data}

What information is required to measure exposures to and from the household sector? First, household-level data is necessary so that the common risks of different types of households can be studied across both different groups and risks of interest. That is, while the units of analysis will typically be groups of households, to characterize exposures among groups of households with differing propensities to consume, for example, one has to have information for many possible groupings defined by demographics

7. In terms of regulatory response, the government can simply disclose these exposures so that government accounting is more informative, or the government can hedge the exposures so that tax rates can be smoothed and market prices better reflect true risks, or finally, it can restrict or intervene to deter the exposures ex ante that lead to bailouts in some states ex post.

8. Mispricing relative to a benchmark in which people are not limited in knowledge or information-processing capacity. 
and/or financial measures of interest such as liquid wealth or home ownership status. Individual-level data allow the study of the history of exposures and behavior of different groups or types of households through different aggregations of historical data. Further, to calculate the exposure of claims on household resources to an aggregate shock, one needs to model the default of each household, which again is most straightforward (and requires the least extraneous assumptions) using household-level data. For example, to predict how much default would accompany a 10 percent decrease in house values for a group of households, it would be useful to know not just that the average loan-to-value ratio of households in that group was 80 percent, but also the distribution of loan-to-value ratios and how correlated other household assets and incomes were with the considered aggregate risks. Finally, the study of household-level data is a useful input to risk calculations, such as under what conditions households default or how different regulations might change household behavior. That is, household-level data allows one to use existing variation in laws, regulation, prices, and so forth across households to study and measure household behavior and thus infer better what losses to and from the sector would occur in response to what aggregate events.

In terms of the information on each household, the arguments in section 13.1 imply that the data contain enough detail on assets, income, and liabilities to accurately measure the extent to which a household's liquid wealth and lifetime wealth are correlated with macroeconomic risk factors. This requires knowledge about the nature of income, of assets held in each asset class, and of credit terms for debt, so that the impact of changes in each on liquid wealth and on total wealth can be calculated. For example, holdings in retirement accounts clearly expose lifetime wealth and not liquid wealth, while temporary shocks to income affect liquid wealth more than lifetime wealth. In sum, a system to monitor systemic risk in the household sector requires data on assets and liabilities both at the household level and in enough detail to assess their roles in liquid wealth and lifetime wealth.

What actual financial information about households is needed? As in the monitoring and regulation of the US banking system, one would like to observe sufficient detail about household balance sheets to accurately measure the exposure of each asset and liability to aggregate risk factors of interest. To this end, the data need to contain information not just on the holdings in any asset class, but on the actual details of the securities held. It is insufficient to measure the risk of a class of assets because one group of households may differ significantly from another in the actual securities held within that class, and so actually have quite a different exposure to a macroeconomic risk factor. As examples, among mortgages, the extent to which households default will differ dramatically with the terms of the mortgage. Stocks can have high exposure to aggregate risk or provide insurance against aggregate shocks. Hedge funds can be highly levered and lose 
money in response to credit shock, or provide liquidity in a credit shock and be highly profitable.

A similar argument applies to labor and benefit income. One needs to know enough details of the labor income of the household to measure the exposure of labor income to macroeconomic risk factors and to measure the household's ability to avoid default or bankruptcy. Some households have stable labor and benefit incomes and others are highly exposed to business cycles. The actual exposures, as for assets, can be estimated from existing data on historical labor incomes of similar households. And benefits and income amounts from each source are necessary to infer total exposure.

Finally, an important part of monitoring banks is the quality of management and its plans for future contingencies. The measurement of financial sophistication in the household sector is similarly important for measuring and monitoring risks and for providing clues as to which risks might be mispriced. In banking regulation, the quality of management informs the regulator about the likelihood that the financial institution can manage the exposures inherent in the bank's asset and liability positions. In the recent financial crisis, measurement of this dimension for Fannie Mae and AIG Financial Products would have shown poor management practices, been easy to correlate with massive exposures to real estate prices and price impact, and potentially been useful to other investors taking prices as informative about the riskiness of mortgage-backed securities. While poorly managed firms tend to suffer a Darwinian fate, this argument has little bite for households living well above subsistence. And regulation today reflects this: regulations restrict most households from making many investment choices, which are available only to qualified investors. ${ }^{9}$

While financial sophistication has many dimensions, the most pertinent to measure is the extent to which households are informed about aggregate risks and their exposures to them. If households are not informed, that is not proof that they are incorrectly exposed, but it suggests that greater information about exposures might change behavior for the better. The measures, discussed later, capture the extent to which households are informed about the financial decisions they are making, the extent to which they have the abilities to make reasonable financial decisions, and the extent to which

9. Would information on sophistication have been helpful before the financial crisis and 2008 to 2009 recession? Probably not (although Lusardi [2010] argues to some extent otherwise). This sort of information on households seems unlikely to have been useful in monitoring the systematic risks and in avoiding them, since closely related data was available. The information in credit ratings bureaus showed that subprime borrowers had very poor credit ratings, which probably correlates highly with lack of financial sophistication. But this does not mean that this type of information will not be useful next time. In the next potential crisis, it might be that households take on more risk than they intend absent LEADS-type information, or that markets or regulators would find information on the sophistication of the households driving financial flows to be a useful signal to help interpret price movements and measure macroeconomic risks. 
Table 13.1

An overview of LEADS for households

Data at the household level on:

Liabilites

Assets

Earnings

Demographics

Financial Sophistication
Measure terms of each borrowing instrument and calculate exposure-collateral information, commitment/term, interest-rate determination, penalties, etc.

Details almost completely lacking in current data sets.

Details on each investment, including restricted accounts like retirement. Examples: name of hedge fund, actual security, house address, etc.

Details almost completely lacking in current data sets.

Measure of current and past incomes at the household level as well as dynamics.

Current data sets strong (PSID, NLSY, CPS, ACS, IRS).

(Age, family structure, geographic location, occupation, industry, etc.)

For grouping households into groups to study exposure, for public data.

Details available but not tied to data other than earnings and course measures of assets and liabilities.

Measures of households' expectations and subjective probabilities of different scenarios and responses to tests of understanding of investment choices and consumption smoothing in the markets in which they are operating.

Completely lacking in current data sets

they exhibit characteristics correlated with good financial decision making. We would better understand macroeconomic risks if we were always able to observe when credit was increasing to households with low financial sophistication and when households with low financial sophistication were increasing their exposures to macroeconomic risks.

In sum, the needed data is information collected at the household level on the following categories, summarized in table 13.1: Liabilities, Assets, Earnings, Demographics, and financial Sophistication (LEADS). Table 13.1 also highlights what is missing from current data sets. The two main missing items are (a) the details on assets and liabilities at the household level, and (b) measures of financial sophistication.

The fact that the LEADS data would contain a host of information on household financial positions raises important issues of privacy. It will be necessary to insure the anonymity of households in any summary statistics released to the public or limited data sets released to researchers. I do not address these issues in this chapter, but merely note that these issues are of great import and surmountable. They are important, as the provision of accurate information in part relies on the confidence of the provider that the information will not be misused. That these issues are surmountable 
is shown by the regulation of the banking sector in which bank regulators have been able to preserve the privacy of confidential bank information. ${ }^{10}$

\subsection{How to Collect the LEADS Data}

How could a statistical agency gather the LEADS data? While the details of the system could rival the documentation of the measurement of risk in the traditional banking sector, in short there are several principles that are necessary to gather this information.

First, the collection of data must rely heavily on administrative data. Survey response rates are declining, and administrative data is increasingly detailed, already computerized, and has low rates of error. Even cooperating households with good intentions are likely not to know the details of their financial contracts or holdings. This happens in two ways. The household may simply not know the details of the asset or liability that are available to them, like a household not knowing the aggregate and idiosyncratic risks of the returns on a stock they own, or whether their mortgage gives the lender recourse or not, or the covenants and seniority of a bond they own. Or the household may not have access to this information, as would be the case for a household holding a mutual fund or hedge fund, or having its investment advisor allocating its assets.

This information, however, is available through financial institutions, all of which are already (or seemingly will be) covered under the large umbrellas of financial regulation and reporting. The organizations that sell the assets or hold claims on households either understand the details of the payments that must be made in different states of the world or have on file the terms of the mortgage contract, the National Securities Identification Number (or CUSIP) of the security, and so forth. One approach is for the appropriate regulator to gather reports on all financial holdings by or against a given household by all financial entities. ${ }^{11}$ The gold standard for information on financial positions - assets and liabilities - is administrative data from the universe of financial institutions, merged by household for a subset of households. The universe of financial institutions would have to include everything from hedge funds to payday lending to limited partnerships. ${ }^{12}$

10. The IRS has also not allowed leaks of confidential tax return documents while allowing researchers to use the data for important social scientific research.

11. There are questions of feasibility and privacy issues that this chapter does not address. Presumably one could gather this administrative data with the consent of the surveyed household. Another option would be to require universal reporting by financial institutions for certain types of financial transactions. Household information is gathered by credit bureaus and households wishing to engage in certain financial transactions are also choosing to be monitored. Tax law requires reporting of all dividends.

12. It is unclear how to handle international holdings, although one could cover a large portion through intermediaries who sell (or lend) from abroad. 
Even if this is not completely possible, it seems necessary to rely as much as possible on administrative data to avoid significant loss in detail on holdings.

Could statistical agencies use private companies that serve households and collect financial information, such as Mint.com? Data from these private money management companies suffers from a serious shortcoming: the sample of the population they cover are not representative of households in the United States. These data cover only households that choose to manage their finances and do so online. Households that use these types of services are not the average household, and in particular they probably display more than average financial sophistication - certainly in the dimension of planning - and so likely have different wealth and incomes and take different financial risks.

Second, household demographics are probably most accurately gathered by a household-level survey or possibly even simply gleaned from existing household surveys. Administrative data may provide better coverage, since any household survey will suffer the usual problems of surveys, including potentially low response rates. But much of the basic demographic and even income data already exists for many households in several extant data sets. Using the various surveys of households conducted by the Census Bureau, and combining data across existing data sets within the US government at the household level could yield an accurate picture of household demographics and income. With household permission, the government agency could merge this extant survey data with the financial information provided by the financial sector to create a close-to-ideal data set. A further improvement would be to merge with the income and tax return data in the Internal Revenue Service. ${ }^{13}$ There are, of course, many hurdles to these coordinated efforts, including issues of consent, issues of biasing responses and data provision, and issues of interference with the primary missions of the original data sources.

Third, financial sophistication can be measured using a combination of data from financial institutions and survey methods. Financial institutions have information on household choices and responses to financial offers. These responses have been used by economists to measure financial sophistication in behavior from dominated choices (see Agarwal et al. 2009, 2010). Detailed holding can also be used to ask to what extent observed behavior conforms to an economic model's views of what optimal behavior ought to be (see, for example, Calvet, Campbell, and Sodini 2007, 2009). In either case, financial institutions have some existing information on the quality of financial management within a given household. However, this information is unlikely to prove sufficient, and the collection of this type of information may distort the incentives for financial institutions to create the information.

13. While historically these data have been very difficult to use for confidentiality reasons, the data at least could be used to construct group-level statistics available outside the IRS. 
Complementarily, many dimensions of financial sophistication can be measured by suvey methods, as shown by existing surveys. A notable example is the Financial Industry Regulatory Authority (FINRA)'s National Financial Capability Study (2009). At this point, however, there is insufficient previous research on the usefulness of different dimensions of sophistication to know exactly which questions or information will be most useful. And to some extent flexibility must be maintained in data collection so that measures can evolve with the financial situation and the risks percieved as potentially most interesting.

Despite these caveats to measurement of financial sophistication, three types of data are potentially useful indicators of suboptimal responses of household spending or mispricing of claims on the household sector. The first type of information is measures of household contingency plans for macroeconomic events of interest. ${ }^{14}$ This information would be directly useful for understanding default on credit instruments and indirectly for modeling whether expectations of actions are inconsistent across households (and potentially financial institutions). The information that everyone plans to run for the same exit in the event of a fire is useful information for households themselves.

The second class of useful information concerns whether households understand the financial products they are using. Lack of understanding would suggest suboptimal exposure to macroeconomic risk factors, and potential exploitation leading to increased aggregate exposures. Of course this is far from proof, as illustrated by the analogy of the pool player who plays well but does not understand classical mechanics. ${ }^{15}$ But there is strong evidence that measures of this type of financial sophistication are correlated with financial choices. ${ }^{16}$

Note that the motivation to measure macroecomomic risk exposure is distinct from the motive to protect investors; that is, the goal of the newly legislated Consumer Financial Protection Agency. While the methods may overlap and the data may be of interest for both purposes, the measurement of aggregate risk exposures requires a focus on common misunderstandings that align with measured exposures.

Finally, the third dimension of sophistication to measure is general abilities and behaviors related to good financial decision making. For example, saving for retirement is much larger among households that report that they plan for vacations (Ameriks, Caplin, and Leahy 2003). While it is probably

14. Brunnermeier, Gorton, and Krishnamurthy (2012) provide a modeling strategy for financial institutions that makes use of these type of questions of financial institutions.

15. Note that an important aspect of the analogy is inconsistent with our modeling of agents as pool players. There is no uncertainty in pool. If an economist's agent played pool, in theory, the agent would always win by sinking all the balls in the right order on the first shot.

16. See, for example, Lusardi and Mitchell (2007). 
not realistic to measure IQ for these purposes, IQ does correlate with financial decision making (Grinblatt, Keloharju, and Linnainmaa 2011).

Turning to the structure of the data, for accurate measures of systemic risk, it will generally be necessary that all data be in the same data set - that is, that one has all LEADS information for a set of households. Short of this, if groups of interest can be defined based on observables that are measured in two different data sets, then the group averages can be constructed for each group in each data set and combined. For example, if assets, liabilities, and income are well measured in one data set with demographics, and financial sophistication is well measured in another data set with demographics, then one can calculate statistics about financial sophistication for any demographic group. What one cannot do is observe if, within any demographic group, it is the less sophisticated households that are holding particular assets held by that group and not other assets. With some loss of accuracy, one can extrapolate from a small sample with complete information to a larger sample with information on different dimensions for different households.

Finally, to what extent is repeated cross-sectional data sufficient, or would the LEADS system be significantly stronger with panel data that follows the same households over time? The risks of assets and liabilities require that one track the performance of these assets, and not that one track the same households over time. To measure income dynamics and correlations with macroeconomic risks requires repeated measures of a household's income, but there are data sets from which measures could be constructed with long time series already. The Panel Study of Income Dynamics, the Current Population Survey, and the Social Security Earnings Records in the Health and Retirement Study all provide long histories of earnings on households that could be mapped to demographics and then applied to households in the new data set. I expect that the heterogeneity within a demographic group missed by this method would be of little systemic interest. That said, repeated cross-sectional data will reduce the power of many measures, particularly when studying household-specific changes to better understand behavior or when tracking the impact of changes over longer periods of time.

\subsection{Outline of LEADS Data Analysis and Dissemination}

The LEADS system is designed to allow the measurement of the exposure of the liquid wealth and lifetime wealth of different groups of households to different macroeconomic shocks and the construction of measures of the exposure of both aggregate consumption demand and claims on the household sector to these macroeconomic shocks. This section first outlines a framework for analysis of three steps: (a) measure the risk exposure of each asset, each liability, and each income stream to macroeconomic 
risk factors; (b) aggregate exposures to household-level liquid wealth and lifetime wealth and then aggregate exposures to groups of households; and (c) model the exposures of aggregate consumption demand, claims on the household sector and government liabilities. Second, dissemination of both analysis and anonymous raw data is critical. While regulators may find patterns of exposure informative, the private sector can also better respond to and price risks when it is better informed of their aggregate consequences, as would be the case if it had access to both the analyses and some of the data.

To begin, the measurement of the risk exposure of assets and liabilities can be based on textbook asset pricing and its application, which necessarily involves the difficulties of the real world. This part of the analysis of the LEADS system is not novel and is reasonably well understood by academics and practitioners. I simply propose standard modeling of asset and debt cash flows that makes up the bulk of quantitative finance and fundamental analysis. ${ }^{17}$ Returns, cash flows, and prices, are described as a sum of exposures (betas) times realizations of aggregate risk factors and idiosyncratic or deterministic components. Modeling income risk is similarly reasonably well understood and applied in labor economics. Here "understood" does not mean straightforward. Perhaps the most important assumptions are those about the behavioral responses over the period studied in cases where these responses affect cash flows, which as noted subsequently, may depend on other holdings of a given household.

Given estimated exposures, the liquid wealth of a household can be written as a sum of stochastic cash flows into and out of liquid assets from income, assets, and liabilities, and of terminal prices of liquid assets and liabilities. And the lifetime wealth of a household can be written similarly, but for all assets (not just liquid assets). Thus, we would have measures of the exposure of these two concepts of wealth to variation in aggregate risk factors. Finally, aggregating across households, one calculates the implications of a change in any set of aggregate factors for the liquid wealth and lifetime wealth for any group of households.

The third step in analysis is to use a model of the consumption sensitivity of different households to these two types of wealth to measure the exposure to aggregate risk factors of the aggregate demand for consumption. As discussed shortly, this requires modeling household behavior. But having modeled household saving, consumption, default, and portfolio behavior, the LEADS system provides a measure of the exposure to default of any set of claims on the household sector. ${ }^{18}$ Finally, one can examine under what

17. One danger going forward is that new financial products have limited histories and so are potentially the most subject to misestimation.

18. Similarly, given decision rules about portfolio choice, one can evaluate the change in asset demand from the household sector. With assumptions about the potential other buyers of the asset, one can check the aggregate risk factor exposures are reasonable or reasonably consistent with the household responses. 
scenarios there are significant direct or possible effects on the government budget through explicit or implicit guarantees or legislative responses.

As noted, the modeling of household behavior is a critical step in the construction of both income and asset/debt outcomes as well as household consumption, saving and rebalancing in response to events. In short, we need to model how households respond to changes over any horizon considered. In terms of risks to the household sector, most relevant are exposures of household income, where cash flows depend on household labor supply responses, and exposures of household debt, where the household can choose to exercise an option to default or change portfolio or saving behavior. In terms of outcomes, the LEADS analysis needs to model household consumption behavior to understand how the demand of different households are more and less exposed to macroeconomic events. Further, to understand claims on households, one has to make assumptions that determine the situations in which households default. Fortunately, many of these behaviors have been or can be measured from past experiences and existing data, so that modeling assumptions can be disciplined by data. Further, one advantage of LEADS data is that, because it represents a significant increase in the quality of available information, it will increase the ability to learn about these behaviors from future events. Nevertheless, given the importance of these assumptions, any analysis will have to carefully evaluate robustness to alternative assumptions.

Household financial sophistication may be quite useful in modeling household behavior. Household decision rules may differ importantly with financial sophistication. The second use of financial sophistication is in grouping households for analysis, in combination with information on exposures. Where exposures - to or from the household sector - are large and sophistication low, this is suggestive that macroeconomic risks may be mispriced or amplified by lack of sophistication or information.

In sum, the proposed analysis produces information on the exposure of aggregate demand to various risks, information helpful for the private sector and the government. The analysis measures the size of risks emanating from the household sector, and allows them to be evaluated and tracked into other sectors of the economy. Finally, the analysis contains information on the potential costs to the government in terms of likely payouts through automatic means-tested programs and possible payouts through ex post bailouts to subgroups of the household sector.

Finally, the LEADS information could be made public, in three ways. First, the results of the analysis - the range of possible impacts on aggregate demand and defaults and asset prices for many aggregate scenarios under any assumptions - could be made public. This dissemination can lead to many benefits, as discussed in section 13.1 and the appendix. Further, if regulators were concerned about the possibility of "unsophisticated" households unintentionally holding too much risk, then particular results about 
riskiness could be pushed to the type of household that might most benefit from this information. Similarly, if regulators were concerned about the exposures of some market participants, they again could highlight the risks and allow participants to react to the information as they see fit.

Second, a data set of aggregated data could be made publically available for analysis and investigation by academics and investors. Ideally this data set would combine analysis and raw data. A large number of government agencies produce detailed tables based on data that they collect through surveys. A reasonable model for the LEADS summary data is the published tables based on the Survey of Consumer Finances (SCF). But the LEADS tables would be better if summary statistics were released by demographic groups of possible interest including financial sophistication, and if the focus were not on current value of holdings but on asset detail and riskiness. Further, it would be useful to observe not just mean holdings, but covariances of holdings across assets within a group and quantiles of holdings - both of which would allow a better understanding of the possibility that large shocks lead to large movements for some households in the group. Finally, to be most useful, the statistics should, to the extent possible, convey information about exposure to both liquid wealth and lifetime wealth.

Third, a household-level data set could be made accessible to researchers working to improve our understanding and modeling of macroeconomic risks and financial stability. In keeping with standard survey data protocols, this data set can omit enough detail to ensure confidentiality and anonymity of individual agents. The data set would be useful to bring new evidence on the behavioral assumptions inherent in the extant measures of systematic exposures.

\subsection{Conclusion}

Macroeconomic shocks can lead to large changes in demand from the household sector and can lead to large changes in cash flows from debt claims on the sector. The LEADS system outlined in this chapter is designed to measure sufficient detail on household liabilities, assets, earnings, demographics, and financial sophistication, to project these large changes.

This LEADS system would help households, firms, and policymakers determine what sources of aggregate risk are most pertinent for claims on the household sector and household demand, and when these exposures are likely to be large. More specifically, the system is designed to allow measurement of (a) the distributional impacts on both the distribution of liquid wealth and lifetime wealth, and the resultant changes in household demand; (b) the effects of balance sheet adjustments on the prices and payouts of claims on the household sector held by other sectors; and (c) the resulting impact on the revenues and liabilities of the government, through possible transfers and de jure and de facto guarantees to the household sector. While 
the scope of the LEADS system implies that this chapter can only provide an overview of the system, methodologies exist for most of the individual component tasks.

While it is beyond the scope of this chapter to lay out a complete framework for macroprudential data analysis and regulation of the household sector, the analogy between banks and households suggests that policymakers want to consider three tools. First, policymakers might consider capital requirements, such as existed in mortgage markets in practice in the period of the conforming mortgage. A related system is the Social Security system, which guarantees/imposes a basic standard of living for elderly households by requiring young households to pay while working for health insurance and basic retirement income when elderly. Second, policymakers might consider restrictions on what financial assets households can use. This regulation is in place as restrictions on what investors can invest in unless they are qualified investors. It seems suboptimal to make this determination based on wealth - errors are made both by excluding sophisticated investors from markets and by allowing wealthy unsophisticated investors to invest in any assets. A better regulation might license an investor on the basis of a test, like what is required to get a driver's license to drive. Finally, the regulator may want to inform the public and warn them about specific exposures, or even lean against the wind and try to change prices, limit access, or tax certain investments or strategies that they see as destabilizing. A good data measurement system is an essential guide to evaluate the benefits and, just as important, the costs of any potential regulation.

\section{Appendix}

\section{Why the Government Has a Role in Monitoring Household Systemic Exposures}

There are two benefits to measuring the exposure of the household sector to systemic risk.

First, as a general principle, in markets the social value of information exceeds its private value. Because information has some of the features of a public good, markets tend to lead to the production of too little information. This result comes from the power of markets to create efficient allocations given the available information. Prices aggregate and convey information to market participants, and optimizing agents can coordinate behavior to efficiently produce and allocate goods. However, this benefit implies that when an individual produces information, others benefit. Thus the social value of information exceeds its private value.

When there is too little information, mistakes are made relative to the 
economy with the socially optimal amount of information. Mistakes will tend to be based on the common information that exists, so that misestimation leads to coordinated mistakes that are by definition macroeconomic if not systemic. Misestimation propagates; misestimation of the positions of the household sector can lead to systemic risk elsewhere.

This externality implies that there is a role for a governmental or quasigovernmental agency to produce information. This is not a new role. The government does this for a large number of macroeconomic variables. The government also regulates the production and disclosure of information by firms. The goal of this chapter-and this NBER project-is to modernize data production and provision, updating it to account for the modern financial landscape and redirecting some of its focus from the measurement of means to the measurement of covariances - risks, and macroeconomic and systemic risks in particular.

There are many potential benefits of more information. Market participants would be able to allocate resources more efficiently across potential outcomes given better information on exposures to aggregate risks in places in the household sector. Better measurement of the risk exposure of consumer demand and claims on household resources would also allow the government and the market to better predict consumption demand, and so better understand risks given their observed prices.

The second reason that the government has a role in monitoring household exposures is that some households lack financial sophistication, due, for example, to a lack of financial knowledge, limited information-processing abilities, and limited time allocated to financial decisions. Thus, some households can make significant financial mistakes relative to the decisions they would make if they had the ability and took the time to collect and process fully all available information and knowledge. The provision of information about the holdings of agents with different levels of sophistication can make behavior closer to that of the full-information or full-sophistication economy, which can increase the information content of prices, and lead to better private decision making and better management of systematic exposures.

When the mistakes of market participants are common, they can lead to noise or bias in prices that other agents are using as sources of information for their choices, and may lead to larger systemic exposure of both household demand and claims on households. ${ }^{19}$ In financial markets, financial institutions that all expect to be able to sell the same assets or all draw on credit but fail to recognize the extent to which other institutions have made the same plans create a systematic risk. For households, this misestimation can create a similar dynamic or exposure. In the recent crisis, households

19. A typical argument is that agents do not make similar mistakes over many time periods, not that many agents do not make similar mistakes at the same time. 
that had planned on using home equity to stabilize consumption across bad shocks found that credit was available only at very high prices and that their collateral values had declined, further limiting the extent of borrowing.

Further, when a sophisticated/informed investor observes a price, they must try to infer the information in this price. This inference can involve estimating the shares of price movement caused by agents with different levels of motivation and sophistication trading in the market. And so the inference could be improved by information on these shares-whether observed prices are due to the actions of other sophisticated/informed investors or instead the actions of unsophisticated investors or "noise traders," whose choices are not based on as much information or are motivated by different concerns. For example, a large exposure among a group of households that are (in some sense) making unsophisticated choices can distort prices and pass systematic risk through the household sector into other parts of the economy through default on claims on the household sector.

Public provision of information about the sophistication of groups of agents who are holding different assets can partly reveal how informative market prices are, and again can lead to, better private sector decision making. ${ }^{20}$

Finally, while it is efficient to have the downside economic risk held by those most willing to hold it, it is generically inefficient to have it held by those least able to understand it or who most underestimate it. Lack of sophistication can be exploited and there is always the risk that this exploitation can cause systemic exposure. ${ }^{21} \mathrm{~A}$ signal of the size of systemic risk is its price. And regulators interested in regulating systemic risks need to be able to observe clues as to whether the risk is correctly priced and correctly placed.

Thus, the LEADS data can be informative about whether downside economic risk is being shifted to the unsophisticated part of the household sector, or passed through the unsophisticated part of the household sector to other systemically important sectors. This argument implies that data collection should support these types of inference and should be designed to provide the information necessary for market participants and good regulatory responses. There may be situations where aggregate risk can be reduced by some consumer financial protection, and where regulation of financial

20. This information would allow lenders to these households to observe their sophistication, which can be useful as a signal of the quality of their financial decision making in other areas. Thus, an investor with insufficiently detailed information (or sophistication) to evaluate the exposure of the household balance sheet might still learn from the disclosed abilities of households that are holding certain assets.

21. While not a group of households, one can make the argument that AIG financial products, by mispricing credit default swaps on mortgage-backed securities, lead market participants to underestimate the exposure of these assets to aggregate risk and lead to its being held in systemically important places. Unsophisticated households could play a similar role in the next crisis. 
choices may avoid "unintentional" systemic exposures. ${ }^{22}$ Even without government intervention, information on sophistication is likely to be useful for targeting the provision of information about systemic exposures (or the provision of the implications of analysis of systemic exposures), with the goal of allowing household and firm choices that are more consistent with those that they would have made given complete information.

\section{References}

Agarwal, Sumit, S. Chomsisengphet, C. Liu, and Nicholas S. Souleles. 2010. "Do Consumers Choose the Right Credit Contracts?" Working Paper. http://www .chicagofed.org/digital_assets/publications/working_papers/2010/wp2010_05 .pdf.

Agarwal, Sumit, John Driscoll, Xavier Gabaix, and David Laibson. 2009. "The Age of Reason: Financial Decisions over the Life Cycle and Implications for Regulation." Brookings Papers on Economic Activity Fall:51-117.

Ameriks, John, Andrew Caplin, and John Leahy. 2003. "Wealth Accumulation and the Propensity to Plan." Quarterly Journal of Economics 118:1007-47.

Bernanke, Ben. 2008. "Remarks on the Economic Outlook." Speech at the International Monetary Conference, Barcelona, Spain (via satellite), June 3.

Brunnermeier, Markus K., Gary Gorton, and Arvind Krishnamurthy. 2012. "Risk Topography." In NBER Macroeconomics Annual 2011, vol. 26, edited by D. Acemoglu and M. Woodford, 149-176. Chicago: University of Chicago Press.

Calvet, Laurent E., John Y. Campbell, and Paolo Sodini. 2007. "Down or Out: Assessing the Welfare Costs of Household Investment Mistakes." Journal of Political Economy 115 (5): 707-47.

2009. "Measuring the Financial Sophistication of Households." American Economic Review 99 (2): 393-8.

Carroll, Christopher D. 1997. "Buffer Stock Saving and the Life Cycle/Permanent Income Hypothesis." Quarterly Journal of Economics 107 (1): 1-56.

Eggertsson, Gauti, and Paul Krugman. 2012. "Debt, Deleveraging, and the Liquidity Trap: A Fisher-Minsky-Koo approach." Quarterly Journal of Economics 127 (3): 1469-1513.

Farhi, Emmanuel, and Jean Tirole. 2012. "Collective Moral Hazard, Maturity Mismatch and Systemic Bailouts." American Economic Review 102 (1): 60-93.

Financial Industry Regulatory Authority. 2009. "National Financial Capability

22. The field of economics has a long history of taking individual choices as optimal and basing policy advice on arguments that rely not on individual mistakes but on market failures due to externalities, for example. Both of the previous arguments - that markets naturally produce too little information and so there is a government role in the provision of information - are in this spirit. However, the field tends to ignore the possibility that agents differ in sophistication and sophisticated agents can regulate the behavior of the unsophisticated and improve welfare. The general commitment to the sovereignty of the decision maker is the real divide between behavioral economics and the rest of the field. In cases where sophistication is about education and information, in theory, revealed-preference tests and utility constructs could lead to welfare measures that proscribe such regulations as welfare improving in the standard approach. Obviously, we are some distance from this point. 
Study, 2009 Questionnaire." http://www.finrafoundation.org/web/groups /foundation/@foundation/documents/foundation/p120537.pdf.

Fisher, Irving. 1933. "The Debt-Deflation Theory of the Great Depressions." Econometrica 1 (4): 337-57.

Gourinchas, Pierre-Olivier, and Jonathan A. Parker. 2002. "Consumption Over the Life Cycle." Econometrica 70 (1): 47-89.

Grinblatt, Mark, Matti Keloharju, and Juhani Linnainmaa. 2011. "IQ and Stock Market Participation." Journal of Finance 66 (6): 2121-64.

Hall, Robert E. 1986. "The Role of Consumption in Economic Fluctuations." In The American Business Cycle: Continuity and Change, edited by Robert J. Gordon. Chicago: University of Chicago Press.

. 2011. "The Long Slump." American Economic Review 101 (2): 431-69.

. Forthcoming. "Household Consumption and Debt Data."In Systemic Risk and Macro Modeling, edited by Markus K. Brunnermeier and Arvind Krishnamurthy. Chicago: University of Chicago Press.

Kaplan, Greg, and Gianluca Violante. 2011. "A Model of the Consumption Response to Fiscal Stimulus Payments." University of Pennsylvania. Unpublished Manuscript.

Krusell, Per, and Anthony Smith. 1998. "Income and Wealth Heterogeneity in the Macroeconomy." Journal of Political Economy 106 (5): 867-96.

Lusardi, Annamaria. 2010. "Americans' Financial Capability." Testimony before the Financial Crisis Inquiry Commission, February. http://fcic-static.law.stanford .edu/cdn_media/fcic-testimony/2010-0226-Lusardi.pdf.

Lusardi, Annamaria, and Olivia Mitchell. 2007. "Baby Boomer Retirement Security: The Roles of Planning, Financial Literacy, and Housing Wealth." Journal of Monetary Economics 54:205-24.

Melzer, Brian T. 2010. "Mortgage Debt Overhang: Reduced Investment by Homeowners with Negative Equity.” Unpublished Manuscript. Kellogg School of Management.

Parker, Jonathan A., and Annette Vissing-Jorgensen. 2009. "Who Bears Aggregate Fluctuations and How?" American Economic Review 99 (2): 399-405.

. 2010. "The Increase in Income Cyclicality of High-Income Households and its Relation to the Rise in Top Income Shares." Brookings Papers on Economic Activity Fall:1-55. 